\title{
Rhizopus Head Rot of Confectionery Sunflower: Effects on Yield Quantity and Quality and Implications for Disease Management
}

\author{
D. Shtienberg
}

Department of Plant Pathology, ARO, The Volcani Center, Bet Dagan 50250, Israel.

Accepted for publication 25 August 1997.

\section{ABSTRACT}

Shtienberg, D. 1997. Rhizopus head rot of confectionery sunflower: Effects on yield quantity and quality and implications for disease management. Phytopathology 87:1226-1232.

The effects of Rhizopus head rot, caused by Rhizopus oryzae, on the yield of confectionery sunflower and its quality were studied in field experiments conducted from 1994 to 1996. The extent of yield loss was related to the crop growth stage at inoculation. When heads were inoculated at the budding stage, loss was not apparent, because inoculated heads were not infected. When inoculated at the anthesis stage, loss was relatively high (42.5 to $99.1 \%$ ), and both the number of achenes per head and the individual achene weight were reduced. When heads were inoculated at the seed development stage, yield was not reduced significantly (although the entire receptacle was rotted). Effects of Rhizopus head rot on measures of yield quality were examined as well. Inoculation with $R$. oryzae did not affect the size of the achenes at any crop growth stage. In con- trast, the incidence of discolored achenes (an external sign of nutmeats with a bitter off-flavor) was affected by the disease at all crop growth stages. A survey in eight commercial fields from 1992 to 1996 found that, by the end of the season, incidence of disease ranged from 2.3 to $17.4 \%$. However, since disease intensified late, resultant yield losses were minor and did not exceed $3.1 \%$. Loss figures were estimated by means of a model that was developed and validated in the field experiments. The disease did affect the incidence of discolored achenes. Thus, the conclusion drawn is that the effects of Rhizopus head rot in confectionery sunflower on crop yield is of minimal concern, at least when disease intensifies late, as was the case in the studied fields, but management of the disease should be considered in some situations. The objectives would be to prevent a reduction in yield quality, not yield quantity.

Additional keywords: Helianthus annuиs, yield loss assessment.
Three species of Rhizopus cause head rot of sunflower (Helianthus annuus) around the world: $R$. oryzae Went \& Prinsen Geerligs (synanamorphs $R$. nodosus Namyslowski and $R$. arrhizus A. Fischer), $R$. microsporus Tiegh., and $R$. stolonifer (Ehrenb.:Fr.) Vuill. (synanamorph $R$. nigricans Ehrenb.) (5). All three Rhizopus species are cosmopolitan in soil and decaying plant debris and are pathogens of many crops. $R$. oryzae causes head rot of sunflower in Israel (1). Initial symptoms of Rhizopus rot in sunflower are small, watersoaked spots on the back of the head. The spots gradually enlarge and, as mycelium invades more of the parenchyma tissue, the receptacle becomes soft and pulpy. Woolly masses of whitish mycelium interspersed with numerous black, spore-producing sporangia may be evident externally and are especially conspicuous in the vicinity of infected achenes. Sporangia are readily disseminated by wind and rain and may also be transferred by insects and birds. Birds may transfer the disease directly from a rotted head to a healthy one with inoculum that adheres to their claws or beaks (1). Sporangia require free water to germinate, but the mycelium can penetrate via wounds only. Wounds may be caused by insects, hail, birds, or mechanical implements such as irrigation equipment $(1,5)$. Head feeding by larvae of several insect species is correlated with the severity of Rhizopus head rot $(7,12)$.

Susceptibility of sunflower to $R$. oryzae changes with the age of the crop. At the bud stage, sunflower heads are resistant to infection; the host begins to become susceptible at the initiation of anthesis, after which, the heads are highly susceptible to infection (1, $7,11,23)$. Infected heads may become rotted completely within 3 to 7 days $(23,24)$, with the rate of rot development depending

Corresponding author: D. Shtienberg; E-mail address: dani@agri.huji.ac.il

Publication no. P-1997-1003-01R

(C) 1997 The American Phytopathological Society mainly on temperature. The disease develops most rapidly at temperatures between 20 and $30^{\circ} \mathrm{C}(22,23)$. Thus, although the disease prevails in most sunflower production areas of the world $(2,9,10$, $12,18,19,25,26,28)$, it is predominant in countries where flowering and seed maturation occur at high temperatures $(4,6,8)$.

Sunflower "seeds" are achenes composed of two major subunits: the "hull," identified botanically as the pericarp, and the "nutmeat," identified botanically as embryonic tissue. The embryo is composed of oil and nonoil fractions (29). The disease may affect both yield quantity and quality depending on the stage of maturation at the time of Rhizopus infection and rot development. Reduced achene weight and achene loss at harvest reduce yield quantity (7). The nature of damage to yield quality is related to whether the crop was grown for oil or for confection. Oil quality is usually defined by the concentration of unsaturated fatty acids (e.g., oleic and linoleic acids) (3). Seed from infected heads give oil with a higher saturated fatty acid content (e.g., palmitic and stearic acids) than oil from healthy heads (21). Rhizopus may also affect the physical properties of the oil (color and saponification value) (17). For confectionery sunflower, achene size is an important quality factor; premium prices are paid for confectionery sunflower with a high percentage of large achenes. Therefore, any factor that reduces achene size reduces quality. Rhizopus invades not only the fleshy receptacle, but sometimes the achene itself. Invasion to the achene results in discoloration of the hull and partial or complete discoloration of the nutmeat. Discolored nutmeats are objectionable in the human food market, because of their appearance and bitter offflavor. The roasting process accentuates the discoloration of the infected achenes $(1,29)$.

The role of Rhizopus in sunflower production is not well documented. To the best of our knowledge, there are no quantitative data on the impact of the pathogen on sunflower yield or its quality. In previous studies, no attempt was made to determine the influence of the disease on total crop yield per se; effects were meas- 
ured only on diseased plants $(1,7,21,17,29)$. The objective of this research was to obtain quantitative information on the potential of Rhizopus to reduce the yield of confectionery sunflower and impair its quality. This information is essential for cost effective disease management. A preliminary report was presented elsewhere (14).

\section{MATERIALS AND METHODS}

General. Experiments were conducted in three phases. First, loss induced by Rhizopus head rot, in relation to the crop growth stage at the time of inoculation, was determined. The experimental units were individual plants, with results used to develop a yield loss model. The relationship between disease incidence and yield, yield components, and yield quality was then determined. The experimental units were field plots (population of plants), and the results were used as an independent data set for validation of the yield loss model. Finally, the loss model was employed for assessment of the loss induced by Rhizopus head rot in a few commercial fields.

The local confectionery sunflower cultivars DY-3 and Givat Oz, both highly susceptible to $R$. oryzae, were sown in all experiments and surveyed fields. Seed were sown on raised beds in the second half of March each year; plants were spaced $0.4 \mathrm{~m}$ apart within rows and $1 \mathrm{~m}$ between rows. The crop was irrigated in all experiments using a surface-drip irrigation system. In one surveyed field, overhead sprinklers were used; the other field was not irrigated. All fields were cultivated according to the recommendations for confectionery sunflower, but no fungicides or insecticides were applied.

Inoculation and disease assessment. Heads were artificially inoculated in the individual plant and field plot experiments. $R$. oryzae inoculum was grown on potato dextrose agar amended with $250 \mathrm{mg} /$ liter of chloramphenicol at $25^{\circ} \mathrm{C}$ for 7 days. A sunflower achene was rubbed on a colony of $R$. oryzae on petri dishes and then inserted into the back of the sunflower head. In this way, the wound necessary for infection was created and the inoculum (mycelia and spores) was introduced into the wound (24). This inoculation technique resulted in uniform infections. Preliminary tests revealed that the rate of rot development in artificially inoculated heads did not differ from that of naturally infected heads (at the same growth stage) and that the site of inoculation (back or front of the head) did not affect the incidence of infection or the rate of rot development.

Disease incidence (proportion of diseased heads) was assessed visually. A head was considered infected if soft rot was visible on an area of at least $3 \mathrm{~cm}^{2}$ at the back of the head. Disease incidence was determined every 5 to 10 days in all experiments and surveyed fields, starting at the anthesis stage (late May to early June) and continuing until physiological maturity (early to mid-July).

At each inoculation and disease assessment date, crop growth stage was determined using a scale developed by Siddiqui et al. (16). According to this scale, the growth of the sunflower plant is divided into five major growth stages (GS) corresponding to establishment (GS 1), vegetative growth (GS 2), floral bud (GS 3), anthesis (GS 4), and seed development (GS 5). Several substages have been recognized within each stage. Since heads are susceptible to infection by Rhizopus only after anthesis, a detailed description of these stages follows. Stage 4 (anthesis): GS $4.1=$ anthesis begins; GS $4.2=$ anthesis in the outer quarter of the inflorescence radius complete; GS $4.3=$ anthesis in half of the inflorescence radius complete, and seed filling in the outer florets commenced; GS 4.4 = anthesis in three-quarters of the inflorescence radius complete, and seed filling in outer florets continues; and GS $4.5=$ anthesis complete, and achenes in the outer florets start to change color from white to gray. Stage 5 (seed development): GS $5.1=$ seed filling continues, head inverted, and achenes in the outer florets have turned black; GS $5.2=$ inflorescence cup and bracts yellow, achenes in three-quarters of the inflorescence radius have turned black; and GS 5.3 = seed hard, stem and leaves dry, and commercial maturity complete.
Experiments with individual plants. The effect of Rhizopus head rot on yield in relation to the crop growth stage at the time of inoculation was determined in two field experiments, in 1994 and 1995. Each week, 20 to 30 heads were sampled and marked using colored plastic staples. In 1994, sampling started at GS 3 and in 1995 at GS 4.3; sampling continued each year until GS 5.3. An attempt was made to sample plants of similar height, head size, and vigor. The plants were divided into pairs according to their crop growth stage. One head from each pair was inoculated, and the other was left as a healthy control for reference. Following inoculation, the heads were inspected weekly until physiological maturity. In a specific pair of plants, whenever the inoculated head was not diseased, or the noninoculated head was infected naturally, that pair was discarded from the experiment. After physiological maturity, heads were harvested individually, heads were manually threshed, and the yield per head was determined. The percent loss imposed by Rhizopus was calculated for each pair of heads by comparing the yield (grams per head) of the healthy $(a)$ and the diseased $(b)$ plants, according to the formula $(a-b) / a \cdot 100$. Whenever the inoculated head was detached due to rotting of the receptacle at the stem attachment, yield loss was assumed to be $100 \%$. Six to 10 replicates (pairs with healthy and diseased heads) were done for each of the crop growth stages (i.e., GS 3 to GS 5.3). A one-tail $t$ test $(P=0.05)$ was employed to test the null hypothesis that yield loss did not differ significantly from zero.

Development of a yield loss model. Based on the experiments with individual plants, a model was developed for predicting the yield loss imposed by Rhizopus head rot in a population of plants. Yield loss was calculated in two steps. First, loss was calculated separately (partial loss) for each of the crop growth stages $(i ; i=$ GS 4.2 to GS 5.3) by multiplying the incidence of heads infected at that crop growth stage $\left(\Delta I_{i}\right)$ by the loss index. The loss index $\left(L_{i}\right)$ reflects the loss imposed when infection occurred at the $i$ th growth stage. Since the time from infection until appearance of symptoms (the incubation period) was only 2 to 4 days, it was assumed that these two events coincided. Then, the total yield loss $(\% Y L)$ was calculated by summing all the partial yield loss values according to the equation

$$
\% Y L=\sum_{i=\mathrm{GS}}^{\mathrm{GS} 5.3} \Delta I_{i} \cdot L_{i}
$$

Experiments with populations of plants. The quantitative relationships between the incidence of Rhizopus head rot and yield, yield components, and yield quality, in relation to the crop growth stage at the time of inoculation, were determined in the field. Three experiments were conducted: one in 1995 (experiment 1) and two in 1996 (experiments 2 and 3). Experimental units were populations of plants (plots); plot size was two rows, 10 to $15 \mathrm{~m}$ long, with 50 to 70 plants each. The exact number of plants in each experimental plot was recorded soon after flowering. An attempt was made to establish variation in disease incidence among experimental plots, so that the whole range of disease incidence, from healthy (or slightly diseased) to completely (or severely) diseased plots, would be included in the analyses. Consequently, different proportions of plants were inoculated in different experimental plots. Inoculation treatments in experiment 1 were $0,40,60,80$, and $100 \%$ of the plants. In experiment 2, inoculation treatments were 0,20 , $40,60,80$, and $100 \%$ of the plants; $0,40,60$, and $100 \%$ of the plants were inoculated in experiment 3 . Plots in experiment 1 were inoculated once, at GS 5.1. Experiments 2 and 3 consisted of a factorial arrangement of three inoculation times (GS 4.4 to GS 4.5, GS 5.1, and GS 5.2) for each inoculation density treatment. Experiments were arranged in randomized block design; there were two replicates for each of the inoculation density $\times$ inoculation date treatments.

After crop maturity, experimental plots were harvested with an experimental combine. Seed from each plot were weighed, and yield (metric tons/hectare) was calculated assuming a planting den- 
sity of 25,000 plants per ha. A sample (about $1 \mathrm{~kg}$ ) was taken from the harvest of each plot for determination of yield components (individual achene weight and number of achenes per head). Individual achene weight (milligrams) was determined by weighing a sample of 200 achenes per plot. Yield of an individual head (grams) was calculated by dividing the harvested yield per plot by the number of heads in that plot. The number of achenes per head was then calculated by dividing the yield per head by the weight of an individual achene.

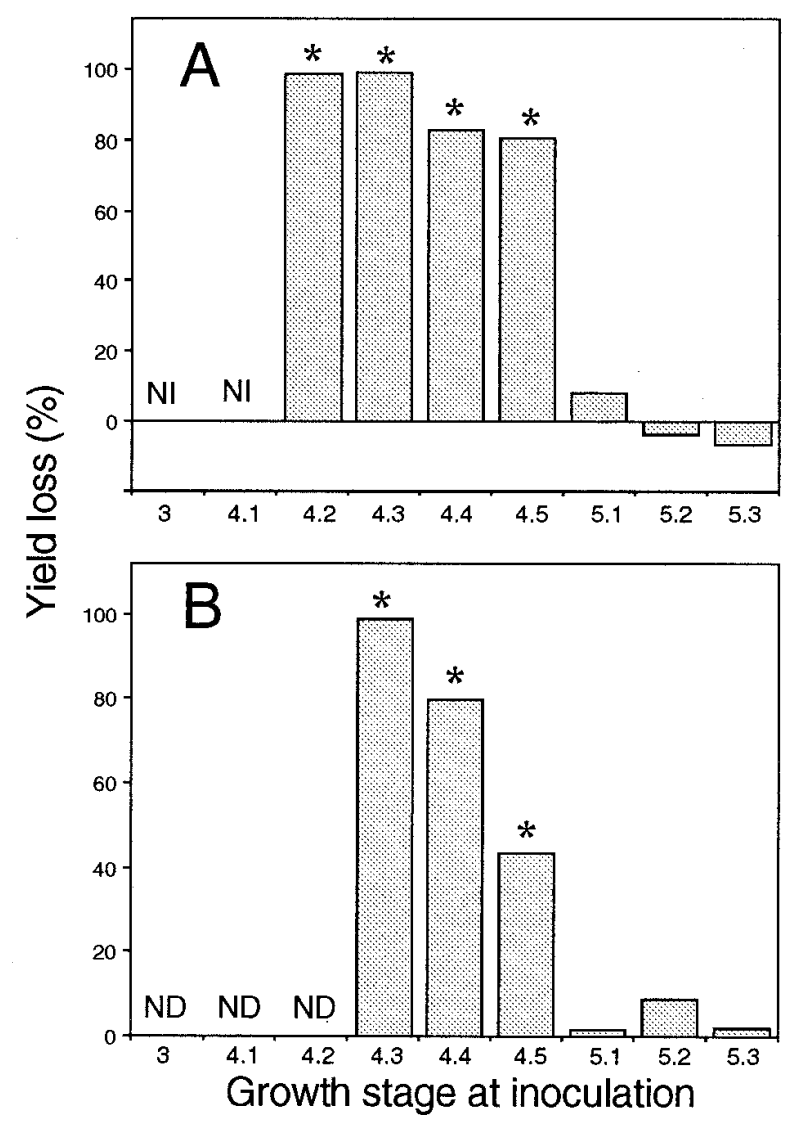

Fig. 1. Effect of Rhizopus head rot (caused by Rhizopus oryzae) on the yield loss of confectionery sunflower in relation to the crop growth stage at the time of inoculation. A, 1994 experiment. B, 1995 experiment. Plants were divided into pairs according to their crop growth stage. One head from each pair was inoculated, and the other was left as a healthy control for reference. Percent loss was calculated for each pair of heads by comparing the yield $(\mathrm{g} / \mathrm{head})$ of the healthy $(a)$ and the diseased $(b)$ plants according to the formula $(a-b) / a \cdot 100$. An asterisk adjacent to a bar indicates that loss is significantly different from zero, as determined by means of a one-tail $t$ test $(P<$ $0.05) . \mathrm{NI}=$ inoculated heads were not infected. $\mathrm{ND}=$ not detected.
Two measures of yield quality were determined: the proportion of large achenes (grade A; percent) and the incidence of discolored achenes (percent). For the first measure, a subsample of $150 \mathrm{~g}$ was taken from the harvest of each plot. Achenes were passed through a serious of round-hole sieves, and the distribution of achene sizes was determined. Achenes that are retained over a $8.7-\mathrm{mm}$ $(22 / 64$ inch) sieve are marketed in the confectionery trade as grade A. Achenes that pass through a $8.7-\mathrm{mm}$ sieve, but are retained over a $7.1-\mathrm{mm}\left({ }^{18} / 64 \mathrm{inch}\right)$ sieve are rated grade $\mathrm{B}$; achenes that pass through a 7.1-mm sieve are not marketed. For determination of the second measure of yield quality, incidence of discolored achenes, a sample of 200 achenes was taken from the harvest of each plot. Each achene was inspected visually for typical Rhizopus head rot symptoms on the hull. A preliminary test revealed that this is a good indicator of nutmeats with a bitter or off-flavor. Achenes were considered discolored if the hull was partially or completely covered with typical dark (brown or black) marks. Symptoms were usually apparent at the part of the achene that was stuck in the receptacle.

Results were analyzed using regression analyses. The independent variable was the observed disease incidence. Dependent variables were yield (metric tons/hectare), average achene weight (milligrams), number of achenes per head, proportion of grade A achenes, and incidence of discolored achenes. Regression equations were computed separately for each inoculation date. Linear regression equations were computed initially. When the linear regression equations were insignificant at $P=0.05$, scatter grams of the data were observed and an attempt was made to fit another linear or nonlinear equation. However, in those cases, it was not possible to fit any other type of relationship between the variables.

The experiments with populations of plants described above were used for validation of the yield loss model. Validation was done by comparing the loss predicted by the model with loss actually observed in the field plots. Predicted yield loss values were calculated for each experimental plot according to equation 1, using disease incidence values recorded during the growing season as inputs. Observed losses were determined for each plot as follows. The intercept of the linear relationship between disease incidence and yield in each experiment was considered as an estimation for the attainable yield $(x ; x=$ metric tons/hectare) in the absence of disease (disease incidence $=0 \%$ ). The loss in each experimental plot was then calculated using the actual yield in that plot $(y ; y=$ metric tons/hectare) as $(x-y) / x \cdot 100$.

Based on the experiments with populations of plants, a model for predicting the damage to yield quality due to discoloration of achenes was developed. It was constructed based on the same principles underlining the yield loss model described in equation 1 , the only difference being that discoloration index $\left(D_{i}\right)$, instead of the loss index, was determined for each crop growth stage. Estimation of the discoloration indexes was based on the slope of the regression equations describing the relationship between

TABLE 1. Statistics for the relationship between the incidence of Rhizopus head rot (caused by Rhizopus oryzae) and yield, yield components, and yield quality of confectionery sunflowers

\begin{tabular}{|c|c|c|c|c|c|c|c|c|c|c|c|c|c|c|c|c|c|c|c|c|c|}
\hline \multirow[b]{3}{*}{ Dependent variable } & \multirow{2}{*}{\multicolumn{3}{|c|}{$\frac{\text { Experiment } 1}{\text { GS } 5.1^{\mathrm{y}}}$}} & \multicolumn{9}{|c|}{ Experiment 2} & \multicolumn{9}{|c|}{ Experiment 3} \\
\hline & & & & \multicolumn{3}{|c|}{ GS 4.4 to 4.5} & \multicolumn{3}{|c|}{ GS 5.1} & \multicolumn{3}{|c|}{ GS 5.2} & \multicolumn{3}{|c|}{ GS 4.4 to 4.5} & \multicolumn{3}{|c|}{ GS 5.1} & \multicolumn{3}{|c|}{ GS 5.2} \\
\hline & $a$ & $b$ & $r^{2}$ & $a$ & $b$ & $r^{2}$ & $a$ & $b$ & $r^{2}$ & $a$ & $b$ & $r^{2}$ & $a$ & $b$ & $r^{2}$ & $a$ & $b$ & $r^{2}$ & $a$ & $b$ & $r^{2}$ \\
\hline \multicolumn{22}{|l|}{ Yield variables } \\
\hline Yield (t/ha) & $\ldots$ & $\ldots$ & $\mathrm{NS}^{\mathrm{Z}}$ & 3.96 & -0.026 & $0.872 * *$ & $\ldots$ & $\ldots$ & NS & $\ldots$ & $\ldots$ & NS & 3.21 & -0.022 & $0.952 * *$ & $\ldots$ & $\ldots$ & NS & $\ldots$ & $\ldots$ & NS \\
\hline No. of achenes/head & $\ldots$ & $\ldots$ & NS & 1,224 & -5.5 & $0.557 *$ & $\ldots$ & $\ldots$ & NS & $\ldots$ & $\ldots$ & NS & 992 & -5.4 & $0.797 * *$ & $\ldots$ & $\ldots$ & NS & $\ldots$ & $\ldots$ & NS \\
\hline Achene weight (mg) & $\ldots$ & $\ldots$ & NS & 131.1 & -0.32 & $0.501 *$ & $\ldots$ & $\ldots$ & NS & $\ldots$ & $\ldots$ & NS & 130.4 & -0.38 & $0.855^{* *}$ & $\ldots$ & $\ldots$ & NS & $\ldots$ & $\ldots$ & NS \\
\hline \multicolumn{22}{|l|}{ Quality variables } \\
\hline Grade A (\%) & $\ldots$ & $\ldots$ & NS & $\ldots$ & $\ldots$ & NS & $\ldots$ & $\ldots$ & NS & $\ldots$ & $\ldots$ & NS & $\ldots$ & $\ldots$ & NS & $\ldots$ & $\ldots$ & NS & $\ldots$ & $\ldots$ & NS \\
\hline Achene discoloration (\%) & -0.46 & 0.17 & $0.696^{* *}$ & -2.6 & 0.39 & $0.931 * *$ & 0.50 & 0.18 & $0.820^{* *}$ & 1.6 & 0.15 & $0.821 * *$ & 1.6 & 0.44 & $0.886^{* *}$ & 0.60 & 0.18 & $0.718^{* *}$ & 0.4 & 0.11 & $0.821^{* *}$ \\
\hline
\end{tabular}

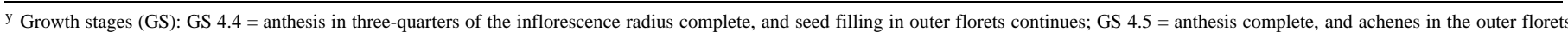
start to change color from white to gray; GS. 5.1 = seed filling continues, head inverted, and achenes in the outer florets have turned black; and GS $5.2=$ inflorescence cup and bracts yellow, achenes in three-quarters of the inflorescence radius have turned black.

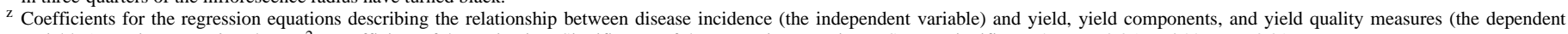
variables). $a=$ intercept; $b=$ slope; $r^{2}=$ coefficient of determination. Significance of the regression equation: NS $=$ not significant; $*=P<0.05 ;$ and $* *=P<0.01$. 
the disease incidence and the incidence of discoloration. The damage to yield quality ( $\% Y Q)$ was calculated according to the equation

$$
\% Y Q=\sum_{i=\mathrm{GS}}^{\mathrm{GS} 5.3} \Delta I_{i} \cdot D_{i}
$$

Estimation of loss in commercial fields. Disease development over time was recorded in eight commercial fields in the northern Negev and Lakhish regions of Israel from 1992 to 1996. Each field was inspected at 5- to 10-day intervals during the growing season. At each date, disease was assessed in each field at four to eight different sampling sites; the number of sites in a particular field being determined according to its size and uniformity. In large (>20 ha) or nonuniform fields, more samples were taken. When examining uniformity, plant height, crop density, and developmental stage were considered. $R$. oryzae infections are distributed randomly within sunflower fields, but disease is more severe close to the field edge (D. Shtienberg, unpublished data). Therefore, within each field, the exact location of sampling was determined arbitrarily, but sampling sites were at a distance of at least $30 \mathrm{~m}$ from the edge of the field. This particular sampling procedure was used previously in disease surveys $(13,20)$. At each sampling site, disease was assessed at four locations, each including 25 consecutive plants in one row. Consecutive plants were sampled to minimize the hazard of sampling bias (i.e., Rhizopus-rotted heads are obvious and attract the attention of the observers). At each sampling date, 400 to 800 plants were inspected in each field. The data were used to calculate the disease incidence for each sampling site, and the field average ( \pm standard error) was then calculated. Yield loss was calculated for each field according to the loss model outlined in equation 1 , and the incidence of discolored achenes was estimated using equation 2 .

\section{RESULTS}

Experiments with individual plants. Disease incidence and loss of yield of individual plants were related to the crop growth stage at inoculation. When inoculations were done at GS 3 and GS 4.1 , inoculated heads were not diseased. Inoculations at GS 4.2 and GS 4.3 resulted in a disease incidence of 30 to $60 \%$, and inoculations done at GS 4.4 or later resulted in $100 \%$ incidence. Similarly, yield of heads inoculated at GS 3 and GS 4.1 were not affected, because no disease developed. When inoculation was done at GS 4.2 to GS 4.5, yield loss was relatively high (42.5 to $99.1 \%$ ) and, in all cases, differed significantly $(P<0.05)$ from noninoculated controls. However, when heads were inoculated at GS

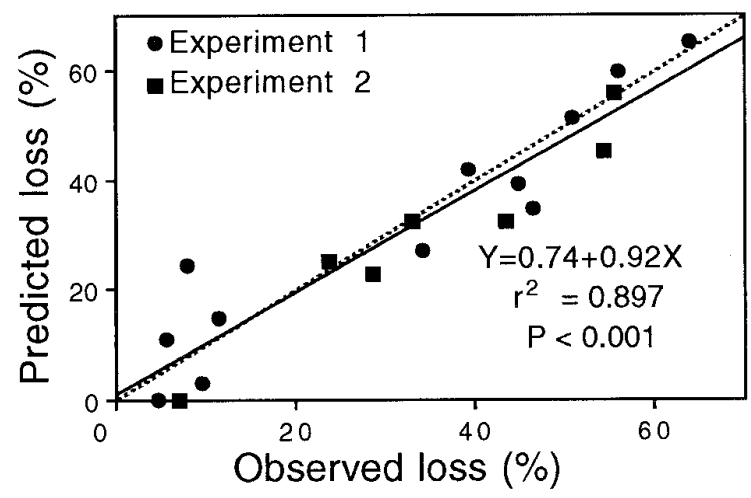

Fig. 2. Model predictions of the yield loss of confectionery sunflower imposed by Rhizopus head rot (caused by Rhizopus oryzae) compared with actual values observed in field experiments. The solid line indicates the regression equation describing the relationship between observed and predicted values. The dashed line indicates the expected relationship for 1:1 correspondence between observed and predicted values.
5.1 to GS 5.3, yield was not reduced significantly, although all heads were infected and the receptacle was completely rotted (Fig. 1).

Experiments with populations of plants. As intended, the various proportions of plant inoculation resulted in a large variation in disease incidence among plots. Disease incidence ranged from 16 to $78 \%$ in experiment 1 , from 2 to $100 \%$ in experiment 2 , and from 4 to $87 \%$ in experiment 3 . Effects of Rhizopus head rot on yield and its components were related to the crop growth stage at the time of inoculation. Inoculation at GS 4.4 to GS 4.5 resulted in a significant linear relationship $(P<0.05)$ between observed disease incidence and yield (Table 1). This implied that the highest yields were obtained in disease-free plants and, as disease incidence increased, yield decreased progressively. The magnitude of that decrease (slope of the regression equation) was $0.026 \mathrm{t} / \mathrm{ha}(0.65 \%$ of the attainable yield per hectare $)$ in experiment 2 and 0.022 t/ha $(0.68 \%)$ in experiment 3 for each percent increase in disease incidence. Yield in plots inoculated at GS 5.1 and GS 5.2 was not correlated with the incidence of head rot, indicating that the disease did not affect yield at these growth stages (Table 1).

Sunflower yield is composed of number of achenes per head and individual achene weight. The relationship between disease incidence and these yield components was significant when plants were inoculated at GS 4.4 to GS 4.5 , but not at growth stages later than GS 4.4 to GS 4.5. Number of achenes per head was reduced by $5.5(0.45 \%)$ in experiment 2 and by $5.4(0.54 \%)$ in experiment 3 for each percent increase in disease incidence; individual achene weight was reduced by $0.32 \mathrm{mg}(0.24 \%)$ in experiment 2 and by $0.38 \mathrm{mg}(0.29 \%)$ in experiment 3 for each percent increase in disease incidence. When inoculations were done at GS 5.1 and GS 5.2 , the relationship between disease incidence and the yield components was insignificant (Table 1).

With respect to achene quality, Rhizopus head rot did not affect the proportion of grade A achenes, irrespective of the crop growth stage at the time of inoculation. Conversely, the relationship between incidence of diseased plants and incidence of discolored achenes was significant for all inoculation dates (Table 1), with the slope of that relationship related to crop growth stage at the time of inoculation. Inoculation at GS 4.4 to GS 4.5 increased discoloration by 0.39 to $0.44 \%$ for each percent increase in incidence of diseased plants. Similarly, inoculation at GS 5.1 and GS 5.3 increased discoloration by 0.17 to $0.18 \%$ and 0.11 to $0.15 \%$, respectively, for each percent increase in incidence of diseased plants (Table 1).

Development and validation of a yield loss model. Experiments conducted with individual plants were used to estimate the yield loss indexes for the loss model (equation 1). Yield loss indexes used were the average of the two individual plant experiments (Fig. 1). Yield loss indexes for the corresponding crop growth stages were GS $4.2=0.991$, GS $4.3=0.982$, GS $4.4=0.825$, GS $4.5=0.610$, GS 5.1 $=0.0311$, GS 5.2 $=0.031$, and GS $5.3=0.0$.

TABLE 2. Predictions of yield loss induced by Rhizopus head rot (caused by Rhizopus oryzae) and the incidence of discolored achenes for eight commercial fields in Israel ${ }^{\mathrm{z}}$

\begin{tabular}{cccc}
\hline Year & Field & $\begin{array}{c}\text { Predicted loss } \\
\text { to harvested yield }(\%)\end{array}$ & $\begin{array}{c}\text { Predicted incidence } \\
\text { of discolored achenes }(\%)\end{array}$ \\
\hline 1992 & 1 & 0.46 & 1.32 \\
1995 & 2 & 1.05 & 1.60 \\
1996 & 1 & 2.91 & 3.63 \\
& 1 & 0.55 & 0.99 \\
& 2 & 0.26 & 0.83 \\
& 3 & 0.07 & 0.33 \\
& 4 & 3.07 & 3.26 \\
& 5 & 1.57 & 2.53 \\
\hline
\end{tabular}

z Yield loss and the incidence of discolored achenes were estimated using equation 1 and equation 2, respectively. Disease progress curves for the corresponding fields are presented in Figure 3. 
The yield loss model was validated using data from the two experiments conducted in 1996 with populations of plants. Analysis was performed initially for each experiment separately, but, since the results of the two experiments did not differ significantly $(P=$ 0.05 ), data were pooled (Fig. 2). The theoretical line indicating a 1:1 correspondence between predicted and observed loss values has an intercept of $0 \%$ and a slope of 1 . The observed regression equation describing the relationship between predicted and observed values had an intercept $(0.74 \%)$ that was not significantly different from $0(P>0.05)$ and a slope $(0.92)$ that was not significantly different from $1(P>0.05)$.

Experiments conducted with populations of plants were used to estimate the discoloration loss indexes (equation 2). Discoloration indexes for each crop growth stage were the slope of the regression equations describing the relationship between incidence of diseased plants and incidence of achene discoloration, averaged over three experiments. Discoloration indexes for the corresponding crop growth stages were GS 4.4 to GS $4.5=0.415$, GS $5.1=$ 0.175 , and GS $5.2=0.13$. The quality loss model was not validated with an independent data set in this study.

Estimation of loss in commercial fields. The progress of Rhizopus head rot was recorded in eight commercial fields in 1992 to 1996. Rot was observed for the first time at GS 4.4, and the incidence of infected heads increased gradually thereafter. There was large variability in final (GS 5.3) disease incidence among fields, ranging from $2.3 \%$ (field 3, 1996) to $17.4 \%$ (field 1, 1992). The yield loss model (equation 1) was used to calculate the loss imposed by Rhizopus head rot on harvested yield. In general, predicted yield losses were relatively low, ranging from 0.07 to $3.07 \%$ (Table 2). The achene discoloration index model predicted quality loss ranging from 0.33 to $3.63 \%$ (Table 2).
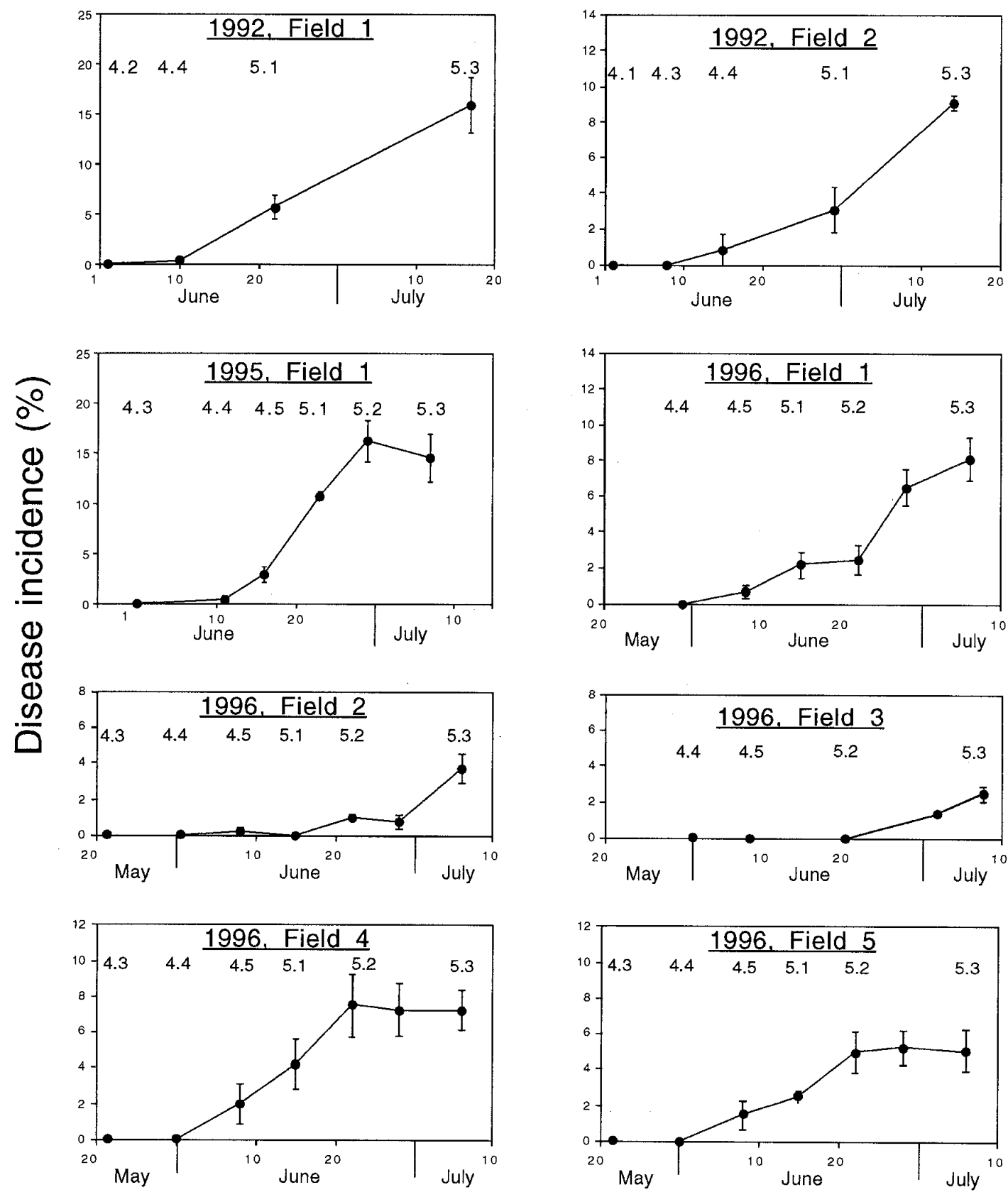

\section{Date}

Fig. 3. Increase in incidence of Rhizopus head rot (caused by Rhizopus oryzae) over time in eight commercial fields of confectionery sunflower in Israel. Bars indicate the standard error for each sampling date. The crop growth stages (GS 4.2 to GS 5.3) are indicated at the relevant dates. 


\section{DISCUSSION}

The severity of losses induced by plant pathogens is often related to the crop growth stage at the time of disease onset and intensification. Occasionally, when disease begins at an advanced stage of crop development, crop yield is not impaired (27). Experiments conducted in this study demonstrated this relationship for the Rhizopus head rot-sunflower pathosystem. Rhizopus infections between GS 4.2 and GS 4.5 resulted in significant yield losses, ranging from 42.5 to $99.1 \%$. However, when infection occurred at GS 5.1 or later, yield was not affected at all, although the receptacle of all infected heads was completely rotted (Fig. 1, Table 1).

The yield loss model that was developed based on experiments with individual plants provided an adequate prediction of the loss when validated in experiments involving populations of plants (Fig. 2). Accordingly, this model was used for assessment of losses in commercial fields. Observed losses in commercial fields were low, ranging from 0.07 to $3.1 \%$ (mean of $1.24 \% \pm 0.41 \%$ ) (Table 2 ). In fact, any attempt to measure such small losses in a replicated experiment would be impractical, since the average experimental error among experimental field plots was about 5\%. Thus, the conclusion drawn is that the effects of Rhizopus head rot in confectionery sunflower on crop yield is of minimal concern, at least when disease intensified late, as was the case in the studied fields.

In contrast, growers of confectionery sunflower in Israel consider Rhizopus head rot to be one of the most important constraints to yield. In this regard, results of this study raise two questions: (i) why were losses observed in surveys so minor, and (ii) why do growers have a mistaken perception as to the importance of this disease? The answer to the first question relates to the crop growth stage at the time of disease onset and development. The growth of individual seed follows a sigmoid curve (3). The start of the linear growth of the pericarp (GS 4.4 in the outer florets) lagged behind anthesis by 5 days and that of the embryo commenced an additional 5 days later, roughly at the time that pericarp weight approaches its final value (GS 4.5 in the outer florets). Since disease onset occurred in most fields at GS 4.5 and because disease intensified later than GS 5.1 (Fig. 3), when seeds had already accumulated most of their weight, yield was no longer affected by the disease and losses were minor. For the second question, the pathogen creates striking contrasts between healthy and diseased plants. Rotted heads, because of their black color, are clearly noticeable within the background of the other healthy, green heads. Moreover, infected heads are not distributed randomly within a field, but, instead, they tend to occur most frequently along the edges of the field. Consequently, a general impression based on visual observation, as opposed to systematic scouting, often leads to biased conclusions concerning disease intensity. Lack of knowledge may also contribute to this misperception. Growers assume that if the receptacles were completely rotted, then yield was reduced, which, based on results of this study, is an incorrect assumption if infection occurs after GS 5.1.

The value of confectionery sunflower is determined not only by crop quantity, but also by its quality. Quality is measured by achene size and taste. Achene size reflects the width of the hull. Head rot incited by Rhizopus had little, if any, influence on achene size (Table 1). This was not surprising, since Rhizopus infection of the fleshy portion of the receptacle occurred after the hulls had already attained their maximum size. The hull develops and reaches its final size at early stages of achene development. Our findings corroborate those published previously for oilseed sunflower (29). The disease, however, did affect the incidence of discolored achenes, an indicator for achenes with a bitter off-flavor. Effects on this parameter were significant for all crop growth stages (Table 1). Estimations made by the quality damage model (equation 2 ) indicate that the incidence of discolored achenes in commercial fields ranged from 0.3 to $3.6 \%$ (mean of $1.94 \% \pm 0.42 \%$ ) (Table 2). Although this range is comparable to that calculated for yield loss ( 0.07 to $3.1 \%)$, the implications are very different. A reduction of
$3 \%$ in yield quantity is negligible; however, if $3 \%$ of the achenes are discolored, the entire crop may be categorized as of low quality. Such categorization may dramatically reduce the net revenue of the growers. The conclusion drawn is that management of Rhizopus head rot in confectionery sunflower should be considered and, in some situations, it should be practiced. The objectives would be to prevent a reduction in yield quality, not yield quantity.

Two approaches may be utilized for Rhizopus head rot management. One possibility is to apply fungicides for suppression of the pathogen. There is only one report of successful fungicide control of Rhizopus head rot, using copper-8-quinolinolate (1). In a set of experiments conducted recently, copper-8-quinolinolate and six other fungicides were applied, but none reduced significantly the incidence of head rot (15). The other possibility for management of Rhizopus head rot is to apply insecticides to control the insects that wound the heads. This strategy has been evaluated on oilseed sunflower $(7,12)$, and preliminary tests have been conducted on confectionery sunflower (15). However, several questions are still open and should be answered before implementation of such an approach. These include quantification of the relationship between insect larvae infestation and Rhizopus head rot incidence, determination of action threshold for insect control, and optimization of insect management.

\section{ACKNOWLEDGMENTS}

This research was supported, in part, by grants from the chief scientist of the Israel Ministry of Agriculture and by the Sunflower Growers' Association. Contribution from the Agricultural Research Organization, The Volcani Center, Bet Dagan 50250, Israel. No. 2079-E, 1997 series.

\section{LITERATURE CITED}

1. Arnan, M., Pinthus, M. J., and Kenneth, R. G. 1970. Epidemiology and control of sunflower head rot in Israel caused by Rhizopus arrhizus. Can. J. Plant Sci. 50:283-288.

2. Bhutta, A. R., Bhatti, M. H. R., Ahmad, S. I., and Ahmad, I. 1993. Prevalence and incidence of sunflower diseases in Pakistan. Hellia 16: 93-98.

3. Connor, D. J., and Sadras, V. O. 1992. Physiology of yield expression in sunflower. Field Crop Res. 30:333-389.

4. Gulya, T. J. 1992. A decade of change: Problems and progress in sunflower pathology from a North American perspective. Pages 49-63 in: Proc. Aust. Sunflower Workshop, 9th. The Australian Sunflower Association, Toowoomba, Australia.

5. Gulya, T. J. Sunflower diseases. In: Sunflower Science and Technology. A. Schneiter, ed. Am. Soc. Agron., Madison, WI. In press.

6. Gulya, T. J., Woods, D. M., Bell, R., and Mancl, M. K. 1991. Diseases of sunflower in California. Plant Dis. 75:572-574.

7. Klisiewicz, J. M. 1979. Relation of infestation with sunflower moth Homoesoma electellum larvae to the incidence of Rhizopus rot in sunflower seed heads. Can. J. Plant Sci. 59:797-801.

8. Klisiewicz, J. M., and Beard, B. H. 1976. Diseases of sunflower in California. Plant Dis. Rep. 60:298-301.

9. Lamarque, C. 1983. Frequency of epidemics of the main sunflower diseases observed in France in the last ten years (1972-1982) and the evolution of their symptoms in relation to climate. Garcia de Orta Ser. Estud. Agron. 10:123-130.

10. Middleton, K. J. 1977. Rhizopus oryzae as a causal agent of a head rot of sunflower in Queensland. Aust. J. Exp. Agric. Anim. Husb. 17:495-498.

11. Mishra, R. P., Kushwaha, U. S., Khare, M. N., and Chand, J. N. 1972. Rhizopus rot of sunflower in India. Indian Phytopathol. 25:236-239.

12. Rogers, C. E., Thompson, T. E., and Zimmer, D. E. 1978. Rhizopus head rot on sunflower: Etiology and severity in the Southern Plains. Plant Dis. Rep. 62:769-771.

13. Shtienberg, D. 1996. Variables associated with intensity of Alternaria leaf spot in Pima cotton. Phytopathology 86:123-128.

14. Shtienberg, D., and Vintal, H. 1997. Effects of head rot, induced by Rhizopus arrhizus, on sunflower yield, its components and quality. (Abstr.) Phytoparasitica 25:240.

15. Shtienberg, D., Zohar, D., Dreishpoun, J., Hefer, Y., and Lior, A. 1996. The role of Helicoverpa (Heliothis) in enhancing sunflower head rot disease and the applicability of its suppression. (Abstr.) Phytoparasitica 24:155.

16. Siddiqui, M. Q., Brown, J. F., and Allen, S. J. 1975. Growth stages of 
sunflower and intensity indices for white blister and rust. Plant Dis. Rep. 59:7-11.

17. Singh, B. K., and Prasad, T. 1977. Effect of seed borne fungi on the physio-chemical properties of sunflower oil. Phytopathol. Z. 90:337-341.

18. Sirry, A. R., Satour, M. M., Zayed, M. A., and Wakil, A. A. 1978. Headrot disease of sunflower in Egypt. Agric. Res. Rev. 56:105-112.

19. Swart, S. H. 1988. Head rot of sunflower in South Africa caused by Rhizopus microsporus. Phytophylactica 20:391-392.

20. Teng, P. S., and Bissonnette, H. L. 1985. Potato yield losses due to early blight in Minnesota fields, 1981 and 1982. Am. Potato J. 62:619-628.

21. Thompson, T. E., and Rogers, C. E. 1980. Sunflower oil quality and quantity as affected by Rhizopus head rot. J. Am. Oil Chem. Soc. 57: 106-108.

22. Wilson, K. I., Al-Beldawi, A. S., and Dwazah, K. 1983. Rhizopus stem rot of Nicotiana glauca. Plant Dis. 67:526-527.

23. Yang, S. M., Morris, J. B., Unger, P. W., and Thompson, T. E. 1979. Rhizopus head rot of cultivated sunflower in Texas. Plant Dis. Rep. 63:
833-835.

24. Yang, S. M., and Thomas, C. A. 1981. Comparison of techniques for inoculating sunflower heads with three species of Rhizopus. Phytopathology 71:458-460.

25. Yang, S. M., Wei, S. E., Ge, C. F., Liang, K. Z., and Wang, L. 1988. Diseases of cultivated sunflower in Liaoning Province, People's Republic of China. Plant Dis. 72:546.

26. Yucer, M. N., and Karaca, I. 1978. Investigations on sunflower diseases in Thrace, their rate and existence, their fungal pathogens and their pathogenicity. J. Turk. Phytopathol. 7:39-50.

27. Zadoks, J. C. 1985. On the conceptual basis of crop loss assessment: The threshold theory. Annu. Rev. Phytopathol. 23:455-473.

28. Zazerini, A., and Tosi, L. 1984. Two new parasites of sunflower in Italy: Rhizopus oryzae Went \& Prinsen Geerligs and Orobanche ramosa L. Inf. Fitopatol. 34:47-49.

29. Zimmer, D. E., and Zimmerman, D. C. 1972. Influence of some diseases on achene and oil quality of sunflower. Crop Sci. 12:859-861. 